\title{
Pelatihan ICT Untuk Pelaku Industri Rumahan di Kabupaten Situbondo
}

\author{
Triawan Adi Cahyanto, Ginanjar Abdurrahman \\ Program Studi Teknik Informatika \\ Fakultas Teknik, Universitas Muhammadiyah Jember \\ Jalan Karimata No. 49 Jember 68122 \\ e-mail: triawanac@unmuhjember.ac.id, abdurrahmanginanjar@unmuhjember.ac.id
}

\begin{abstract}
ICT (Information and Communication Technology) atau lebih dikenal dengan teknologi informasi dan komunikasi (TIK) merupakan aspek yang sedang berkembang dan banyak digunakan di berbagai bidang. Kabupaten Situbondo merupakan salah satu kabupaten yang terletak di ujung timur utara pulau jawa. Mayoritas penduduk di Kabupaten Situbondo, terutama untuk perempuan bekerja sebagai pemilik industri rumahan. Pelaku industri rumahan di Kabupaten Situbondo tergolong masih banyak yang belum menerapkan teknologi untuk menunjang pekerjaannya. Pelatihan ICT ini diadakan agar pelaku industri rumahan yang didominasi oleh perempuan, dapat memanfaatkan ICT sebagai teknologi tepat guna. Berdasarkan data kuesioner ketika pelatihan selesai dilaksanakan, dari jumlah peserta sebanyak 50, angka indeks kesiapan pelaku industri rumahan setelah diproses adalah sebesar 2,99 (sudah hampir siap).
\end{abstract}

Keywords: ICT, Industri Rumahan, Teknologi Informasi, Sosial Media, Pemasaran Produk

\section{Latar Belakang}

Perkembangan teknologi informasi dan komunikasi (TIK) seperti komputer dan teknologi telekomunikasi khususnya internet dapat digunakan dalam menjembatani informasi dan pengetahuan yang tersebar pada pelaku industri rumahan [1]. Akses terhadap komunikasi digital membantu meningkatkan pengusaha terhadap peluang perdagangan dan pemasaran, akses informasi untuk pelatihan, mendapatkan jaringan dan peluang pendapatan bagi perempuan dan meningkatkan peluang tenaga kerja [2].

Teknologi Informasi Komunikasi (TIK) dapat menjadi alat yang efektif bagi para perempuan usaha kecil menengah untuk mengembangkan usahanya. Namun demikian, peran perempuan di dalam perkembangan ICT masih minoritas. Laki-laki masih memegang peranan penting dalam TIK. Perempuan mendominasi pada posisi administrasi, memasukkan data, operator komputer, dan sejenisnya, selebihnya dipegang laki-laki. Dengan kata lain, TIK bagi perempuan di negara berkembang merupakan barang mewah yang sulit dan mustahil diakses. Oleh karena itu dalam rangka pengembangan industri rumahan yang umumnya di dominasi oleh kaum perempuan, perlu dilakukan pengembangan keahlian dalam hal pengoperasian teknologi informasi komunikasi (TIK) untuk meningkatkan produktiitas pelaku ekonomi [3].

Diharapkan dari pelatihan ini para peserta dapat mengenal ICT bagi industri rumahan, mampu melakukan pencarian informasi menggunakan internet, mampu menghitung biaya produksi dan harga jual, mampu memasarkan produk menggunakan media sosial, mampu membuat surat menyurat menggunakan komputer dan mampu membuat profil usahanya sendiri untuk pengajuan kebutuhan dana.

\section{Metode Pelaksanaan}

Jadwal pelatihan bertempat di SMK 1 Panji Situbondo dan dilaksanakan selama 300 menit dengan 6 (enam) materi yang disampaikan. Adapun sebaran waktu yang dijadwalkan untuk setiap materi adalah: 


\begin{tabular}{|c|c|c|c|}
\hline No & $\begin{array}{l}\text { Materi kegiatan } \\
\text { pelatihan }\end{array}$ & Durasi waktu & $\begin{array}{c}\text { Waktu } \\
\text { pelaksanaan }\end{array}$ \\
\hline 1 & $\begin{array}{l}\text { Pengenalan } \\
\text { ICT }\end{array}$ & 15 & $08.30-08.45$ \\
\hline 2 & $\begin{array}{l}\text { Mencari } \\
\text { informasi } \\
\text { menggunakan } \\
\text { internet }\end{array}$ & 60 & $08.45-09.45$ \\
\hline 3 & $\begin{array}{l}\text { Menghitung } \\
\text { biaya usaha }\end{array}$ & 60 & $09.45-10.45$ \\
\hline 4 & $\begin{array}{l}\text { Melakukan } \\
\text { pemasaran } \\
\text { melalui media } \\
\text { sosial dan } \\
\text { pembuatan } \\
\text { brosur } \\
\text { sederhana }\end{array}$ & 75 & $10.45-12.00$ \\
\hline 5 & $\begin{array}{l}\text { Membuat } \\
\text { korespondensi }\end{array}$ & 45 & $13.00-13.45$ \\
\hline 6 & $\begin{array}{l}\text { Profil usaha } \\
\text { dan proposal } \\
\text { pengajuan } \\
\text { kebutuhan } \\
\text { dana }\end{array}$ & 45 & $13.45-14.30$ \\
\hline
\end{tabular}

Metode penyampaian materi dilakukan dengan cara ceramah dan praktik secara langsung sesuai dengan studi kasus yang dimiliki oleh peserta pelatihan. Sarana dan prasarana dalam menunjang pelatihan ICT untuk pelaku industri rumahan terdiri dari prasarana ruangan, sarana laboratorium komputer, buku panduan bagi peserta, sarana penunjang TIK seperti koneksi internet, LCD proyektor, dan lain sebagainya.

\section{Hasil dan Analisa}

\subsection{Pelaksanaan Kegiatan}

Kegiatan pelatihan ICT IR bagi pelaku industri rumahan di Kabupaten Situbondo berjalan dengan lancar. Hampir semua materi tersampaikan hanya terdapat beberapa yang belum sempat disampaikan karena keterbatasan waktu. Pelaku industri rumahan Kabupaten Situbondo berharap untuk mengadakan kegiatan seperti ini kembali sebagai tindak lanjut dari pelatihan yang sudah diadakan saat ini.

\subsection{Analisa dari Kuesioner}

Evaluasi pelatihan ICT untuk pelaku industri rumahan dilakukan melalui penyebaran Kuisioner dalam mengukur efektifitas pelatihan. Peserta diminta mengisi kuisioner yang telah dipetakan terhadap pemetaan situasi dan kondisi ekosistem ICT penyelenggara pelatihan. Terdapat sejumlah dimensi pembentuk ekosistem ICT dalam lingkungan kegiatan pelatihan ini yaitu:

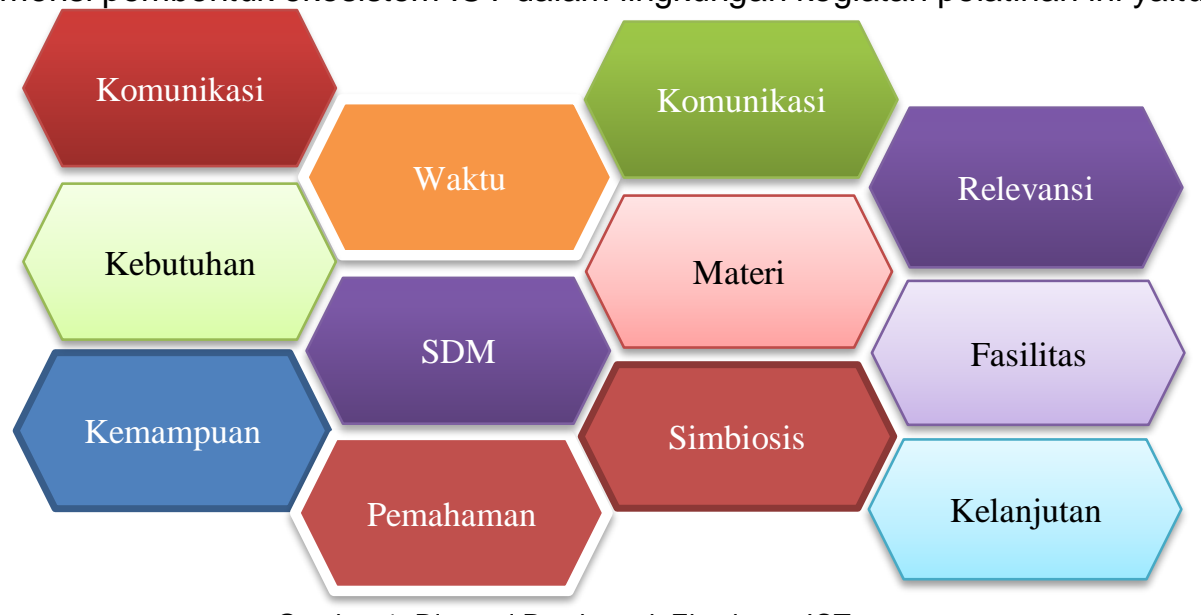

Gambar 1: Dimensi Pembentuk Ekosistem ICT 
Keseluruhan dimensi diatas pada dasarnya saling berhubungan dan tidak terpisahkan satu dengan lainnya. Dalam model perhitungan lebih detail akan sangat bergantung pada konteks, obyektif dan kesiapan penyelenggaraan pelatihan. Terkait dengan Pelatihan ICT, sejumlah prinsip dengan menggunakan rumus:

$$
\text { Indeks ICR Responden }=N R
$$

Dimana:

$N R=$ nilai Rata-Rata

Sesuai dengan sistem "scoring" yang dipergunakan dalam kuisioner pemetaan, maka nilai Indeks ICT akan berkisar 1 (terendah) hingga 5 (tertinggi). Adapun arti indeks tersebut adalah:

1 = Pelaku IR sama sekali tidak siap

2 = Pelaku IR masih jauh dari siap

3 = Pelaku IR sudah hampir siap

4 = Pelaku IR telah siap

$5=$ Pelaku IR telah siap dan mampu bersaing

Oleh karena itu, berdasarkan hasil olahan kuisioner yang telah di sebarkan ke 50 peserta (responden) maka indeks kesiapan pelaku IR khususnya di Kabupaten Situbondo dinyatakan score 2.992 (Pelaku IR sudah hampir siap). Jika dipetakan ke dalam grafik tentang penggunaan perangkat ICT yang digunakan oleh pelaku industri rumahan terlihat pada grafik dibawah ini:

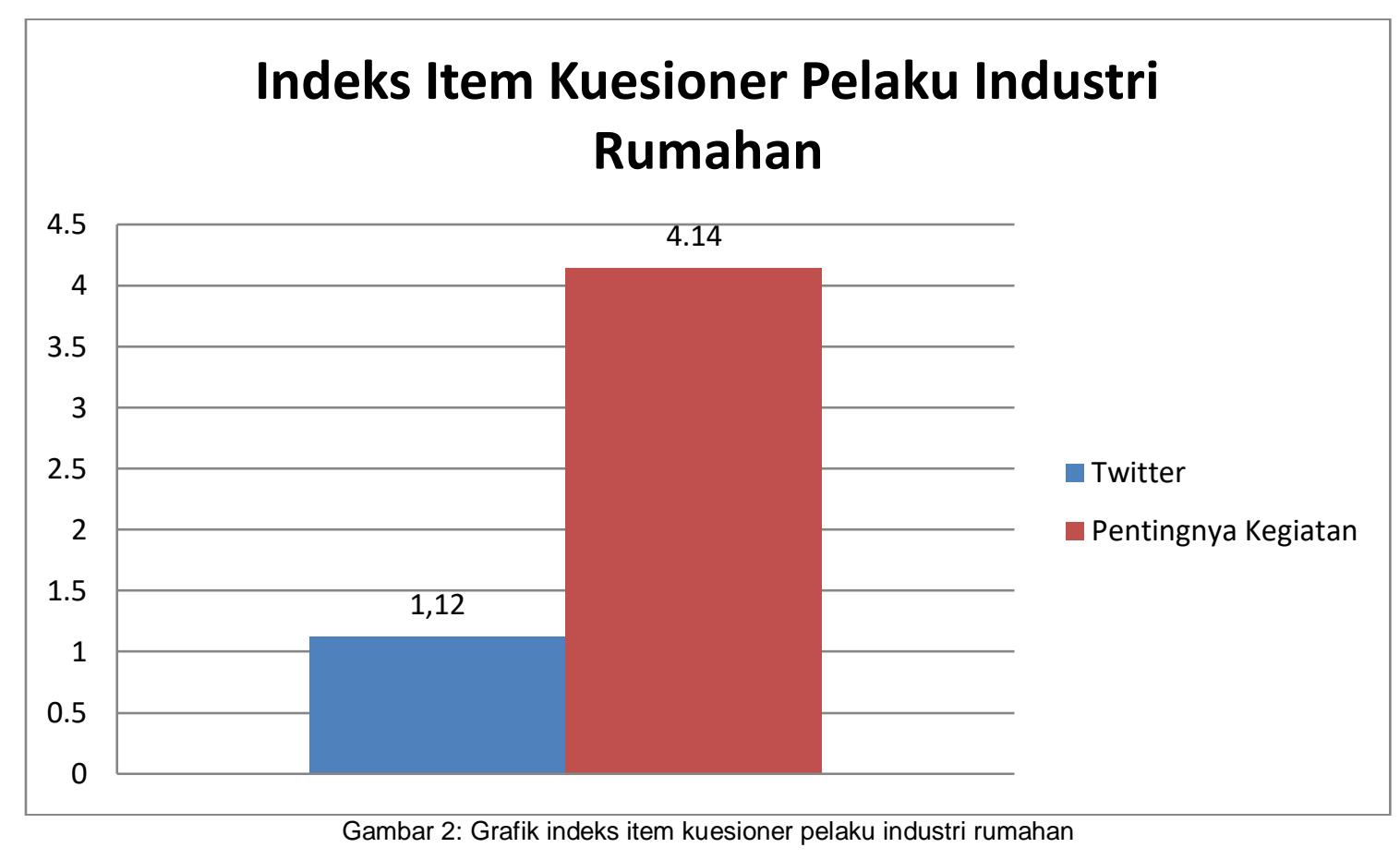

Dari grafik diatas menunjukan bahwa Indeks item kuesioner pelaku industri rumahan paling tinggi adalah pentingnya ikut sebagai peserta kegiatan pelatihan ICT mencapai 4,14, sedangkan paling rendah adalah penggunaan Twitter oleh peserta sebesar 1,12.

\subsection{Hasil Kuesioner}

Para pelaku industri rumahan dalam melakukan bisnis banyak menggunakan media sosial, beberapa media sosial yang mereka sering gunakan berdasarkan hasil survey dapat digambarkan ke dalam grafik dibawah ini: 


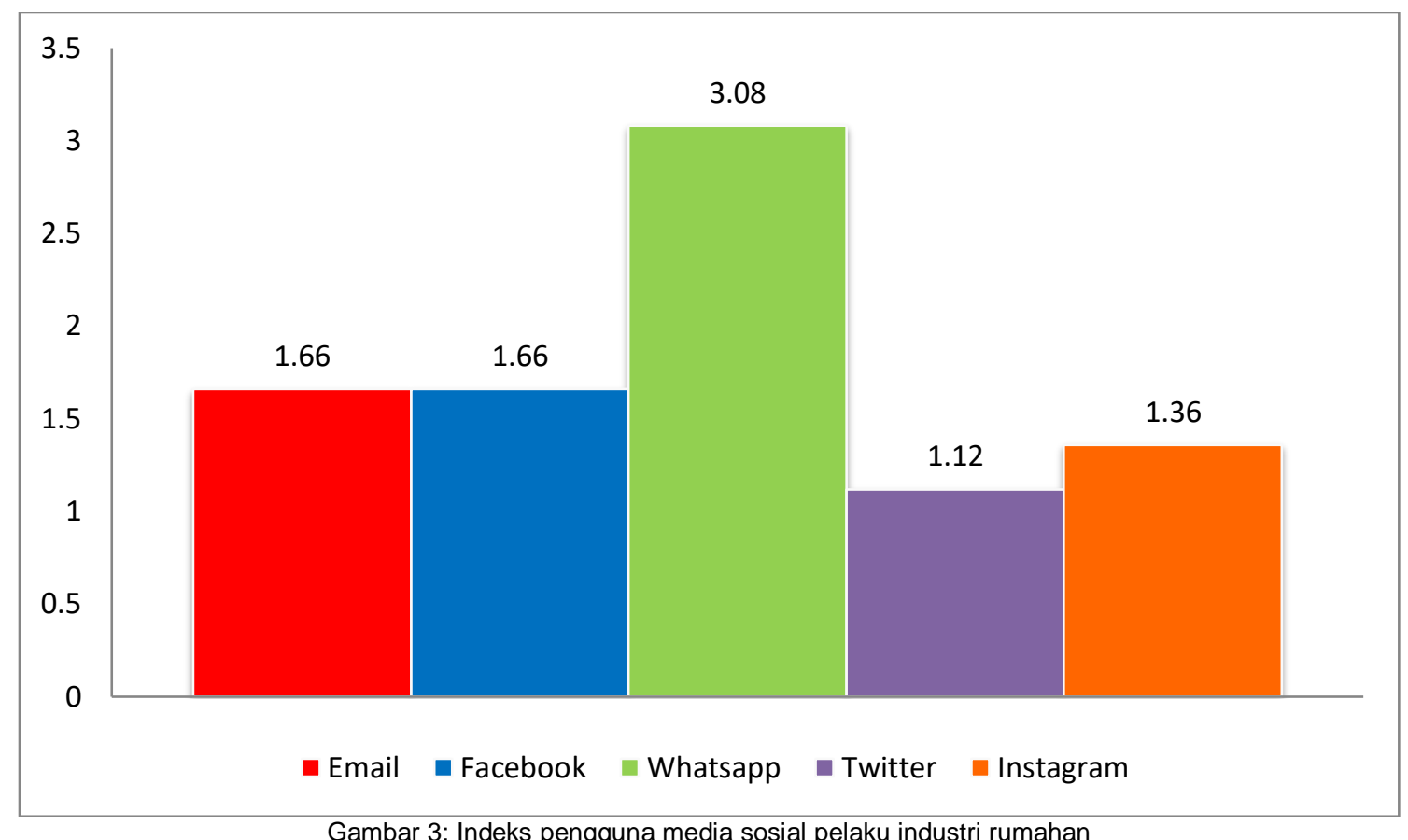

Berdasarkan grafik diatas terdapat temuan bahwa media sosial yang digunakan oleh pelaku industri rumahan dalam berkomunikasi atau menjalankan bisnisnya adalah menggunakan Whatsapp dengan indeks 3,08 sedangkan indeks terendah untuk media sosial yang digunakan adalah twitter dengan indeks 1,12. Telah dilakukan penilaian terhadap beberapa dimensi tentang keberhasilan kegiatan pelatihan ICT bagi pelaku industri rumahan, dengan demikian hasil dari survey dapat ditunjukan melalui grafik dibawah ini:

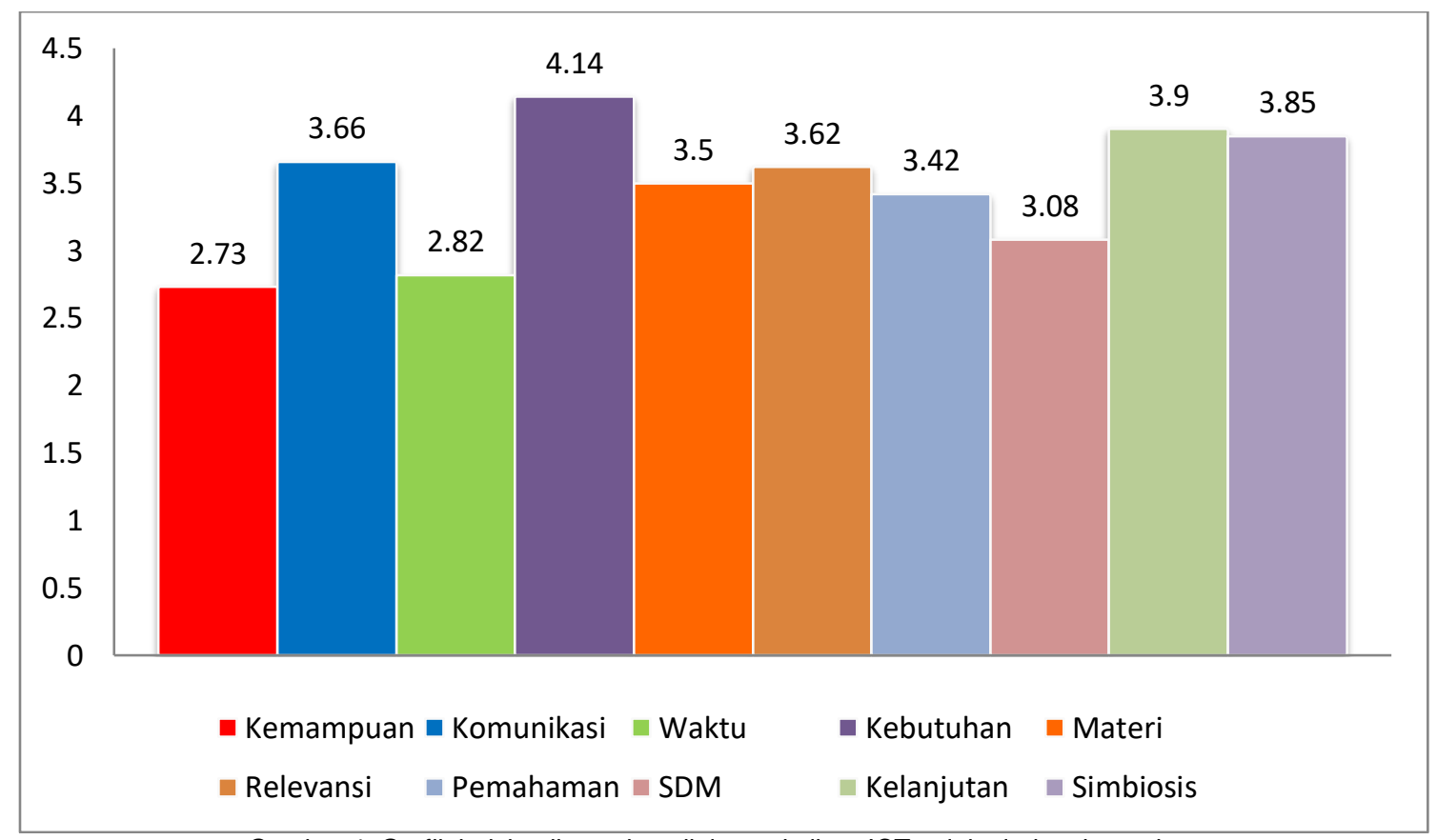

Gambar 4: Grafik indeks dimensi penilaian pelatihan ICT pelaku industri rumahan

Dari grafik diatas menunjukan bahwa tingkat pemahaman dari hasil pelatihan ICT bagi pelaku industri rumahan sebesar 3,42 . Hal tersebut berarti peserta pelatihan ICT bagi pelaku industri 
rumahan cukup dipahami terhadap materi yang disampaikan oleh para instruktur / trainer. Namun demikian terdapat temuan terhadap dimensi kemampuan yang menunjukan indeks penilaian pelatihan sebesar 2.73 (paling rendah), hal tersebut berarti bahwa aspek kemampuan peserta masih perlu ditingkatkan.

\section{Rekomendasi dan Kesimpulan}

\subsection{Rekomendasi}

Berdasarkan hasil evaluasi diatas maka kami dapat memberikan rekomendasi, secara umum pelaksanaan kegiatan pelatihan ICT bagi pelaku industri rumahan cukup dipahami oleh peserta. Dimensi secara umum pun memiliki indeks rata rata lebih dari 3.00, yakni 3.04, hal ini dapat dikatakan bahwa pelaksanaan kegiatan pelatihan ICT bagi pelaku industri rumahan Kabupaten Situbondo adalah berhasil. Sebagai upaya dan tindak lanjut ke depan maka diharapkan kemampuan peserta diseragamkan agar pelaksanaan kegiatan lebih efektif, dan tingkat pemahaman yang maksimal.

\subsection{Kesimpulan}

Kegiatan Pelatihan ICT IR sudah dilaksanakan dengan lancar dan sangat baik. Antusiasme peserta pelatihan dan rasa ingin tau yang tinggi membuat pelatihan ini menjadi menarik. Adapun hasil yang sudah dicapai berdasarkan kuesioner pelatihan ini adalah Wilayah Kabupaten Situbondo sudah hampir siap dengan adanya teknologi informasi dan komunikasi. Kebanyakan masyarakat Kabupaten Situbondo sudah paham teknologi didukung penggunaan ponsel dan sosial media untuk promosi produk usaha lokal.

\section{Referensi}

[1] T. A. Cahyanto, "Implementasi Smart Router Berbasis OpenWRT Sebagai Media Untuk File Sharing dan Chatting Pada Laboratorium Terpadu Unmuh Jember," 2018.

[2] K. P. P. dan P. A. R. Indonesia, Buku Panduan Peserta untuk Industri Rumahan. 2017.

[3] K. P. P. dan P. A. R. Indonesia, Buku Panduan Instruktur Untuk Pelatihan ICT Bagi Pelaku Industri Rumahan. 2017. 